\title{
The Relationship Between Clinical Trial Participation and Inhaler Technique Errors in Asthma and COPD Patients
}

This article was published in the following Dove Press journal: International Journal of Chronic Obstructive Pulmonary Disease

\author{
Rubeshan Perumal (D) \\ Marcia Leite ${ }^{2}$ \\ Richard Nellis van Zyl- \\ Smit (iD) ${ }^{1,2}$ \\ 'Division of Pulmonology, Department of \\ Medicine, Faculty of Health Sciences, \\ University of Cape Town, Western Cape, \\ South Africa; ${ }^{2}$ UCT Lung Institute, \\ University of Cape Town, Western Cape, \\ South Africa
}

Background: Incorrect inhaler use is associated with poorer health outcomes, reduced quality of life, and higher healthcare utilisation in patients with asthma and COPD.

Methods: We performed an observational study of pressurized metered-dose inhaler technique in patients with asthma or COPD. Patients were assessed using a six-point inhaler checklist to identify common critical inhaler technique errors. An inadequate inhaler technique was defined as the presence of one or more critical errors. A multivariate logistic regression model was used to determine the odds of an inadequate inhaler technique.

Results: During the 14-month study period, 357 patients were enrolled. At least one critical error was executed by $66.7 \%$ of participants, and $24.9 \%$ made four or more critical errors. The most common errors were failure to exhale completely prior to pMDI activation and inhalation (49.6\%), failure to perform a slow, deep inhalation following device activation (48.7\%), and failure to perform a breath-hold at the end of inspiration (47.3\%). The risk of a critical error was higher in COPD patients (aOR 2.25, 95\% CI 1.13-4.47). Prior training reduced error risk specifically when trained by a doctor (aOR $0.08,95 \%$ CI $0.1-0.57$ ) or a pharmacist (aOR 0.02, 95\% CI 0.01-0.26) compared to those with no training. Previous clinical trial participation significantly reduced error risk and rate: $<3$ trials (aOR $0.35,95 \%$ CI 0.19-0.66) and $\geq 3$ trials (aOR $0.17,95 \%$ CI 0.07-0.42). The rate of critical errors was not significantly associated with age, sex, or prior pMDI experience.

Conclusion: This study found a high rate of critical inhaler technique errors in a mixed population of asthma and COPD patients; however, prior training and, in particular, multiple previous clinical trial participation significantly reduced the risk of errors.

Keywords: inhaler, pressurised metered-dose inhaler, clinical trials, asthma, COPD

\section{Introduction}

Obstructive airways diseases, including asthma and chronic obstructive pulmonary disease (COPD), are common worldwide. ${ }^{1}$ Inhaled therapies such as inhaled corticosteroids and bronchodilators are the mainstay of treatment of obstructive airways diseases and are preferential to systemic therapies. ${ }^{2,3}$ Inhalation with subsequent airway deposition targets the site of disease, allows for reduced drug exposure, and minimises the risk of systemic side-effects. ${ }^{4}$ Inhaled therapies in both asthma and COPD have been associated with a significant reduction in morbidity and mortality, while non-adherence to inhaler therapy is widely associated with poorer outcomes. $^{5-7}$ Adherence to inhaled therapy implies both regular as well as the correct use in accordance with the prescription, using the appropriate technique and
Correspondence: Rubeshan Perumal Email rubeshanperumal@gmail.com
International Journal of Chronic Obstructive Pulmonary Disease 2020:15 1217-1224

1217

DovePress $f$ in $\boldsymbol{t}$

http://doi.org/10.2147/COPD. $\$ 249620$ (c) (i) (5) 2020 Perumal et al. This work is published and licensed by Dove Medical Press Limited. The full terms of this license are available at https://www.dovepress.com/terms. C. ${ }_{\mathrm{BY}} \mathrm{NC}$ php and incorporate the Creative Commons Attribution - Non Commercial (unported, v3.0) License (http://creativecommons.org/licenses/by-nc/3.0/). By accessing the work you hereby accept the Terms. Non-commercial uses of the work are permitted without any further permission from Dove Medical Press Limited, provided the work is properly attributed. For permission for commercial use of this work, please see paragraphs 4.2 and 5 of our Terms (https://www.dovepress.com/terms.php). 
dosing schedule. ${ }^{4,8-11}$ The correct device-specific technique is required to optimise drug delivery, which requires patients to have an understanding and mastery of these variant skills. ${ }^{4}$ An incorrect inhaler technique is associated with treatment failure, unnecessary escalation of therapy, and increased exacerbations with unplanned use of medical services and hospitalisation. ${ }^{4,7,12-15}$

Pressurised metered-dose inhalers (pMDIs) are the most widely prescribed inhaler devices given their relatively low cost and ability to deliver a wide variety of bronchodilators, inhaled corticosteroids and combinations thereof. $^{16,17}$ Each standardised metered-dose aerosol plume is dispensed upon depression of the canister and requires coordination of the timing of the canister depression with a slow and deep inhalation to deliver the drug to the targeted airways. In addition, a breath-hold at the end of inspiration is required to optimise deposition, mainly by enabling sedimentation. If the basic steps of the inhalation effort (too slow or too fast) or breath-holding are inadequate, airway deposition is compromised. Despite their ubiquity in asthma and COPD management, pMDI technique is inadequate in the majority of users and may remain imperfect even after expert training. In a large study of 5000 structured inhaler technique assessments in patients with moderate-to-severe asthma, 92\% of patients made at least one potentially important error when using a pMDI. $^{6}$ A meta-analysis of 2634 inhaler technique assessments from 10 studies revealed that $45.6 \%$ of patients made at least one critical error when using a pMDI. ${ }^{18}$ The most common pMDI technique errors include failure to perform full exhalation prior to drug inhalation (48\%), failure to breath-hold following drug inhalation $(46 \%)$, lack of coordination between device activation and inhalation (45\%), and inappropriate inhalation velocity (44\%). ${ }^{19}$ The only African study included in the aforementioned review revealed correct pMDI use in only $22.1 \%$ of asthmatic patients and found higher educational attainment and better asthma control to be associated with correct pMDI use. ${ }^{20}$

The evidence to support device education and inhaler technique training for improving inhaler technique is heterogeneous in terms of the nature of the required intervention, but generally supports the partial effectiveness of training interventions. A major limitation of interventions aimed at improving inhaler technique is the lack of standardised definitions for critical and non-critical errors, and lack of widely validated checklists for specific devices. In addition, the threshold for clinically significant error has not been fully elucidated. The most widely used metrics for reporting inhaler technique error are the proportion of patients with one or more critical errors and the average overall (critical or non-critical) error rate. ${ }^{18}$ In a systematic review of 39 randomised studies of the effectiveness of educational inhaler technique interventions in asthma and COPD patients, over $90 \%$ reported a significant improvement in inhaler technique which persisted up to the median follow-up time of 5 months. ${ }^{21}$ Factors associated with intervention success included poorer baseline inhaler technique, educational interventions in the outpatient setting, and advancing age. The provision of general disease education, number or length of intervention sessions, profession of the educator, type of intervention (live demonstration vs video demonstration vs oral presentation), and format of the education (individual vs group), had no clear impact on the effectiveness of the intervention. $^{21}$ None of the 39 studies included in the systematic review was conducted in Africa.

Inhaler technique has been shown to be better within a clinical trial irrespective of device type. ${ }^{18}$ Potential selection bias, specific device-orientated training or the Hawthorne effect, whereby patients may modify their inhaler technique in response to their awareness of being the subject of observation, may be responsible. ${ }^{6}$ It is less clear whether patients maintain adequate inhaler technique beyond the clinical trial as no studies, to our knowledge, have reported follow-up of inhaler technique beyond the trial period.

This study aimed to evaluate the inhaler technique of patients with asthma or COPD using at least one pMDI and to determine if previous clinical trial participation impacted on current inhaler technique.

\section{Methods}

This was a cross-sectional study of pMDI technique in patients with asthma and COPD at a specialist respiratory service and clinical trial unit in Cape Town, South Africa. Consecutive adult patients with a physician diagnosis of asthma or COPD who were using at least one pMDI were included in the study. Patients under the age of 18 years, pregnant women, active clinical trial participants, and patients with pulmonary tuberculosis were excluded from the study. As part of the screening lung function assessment, patients were required to demonstrate their pMDI technique under direct observation. A structured six-point checklist (Figure 1) had previously been implemented to consistently evaluate the demonstrated technique and to 


\begin{tabular}{ll}
\hline Critical Step & Action \\
\hline $\mathbf{1}$ & Shake the inhaler \\
\hline $\mathbf{2}$ & Complete exhalation \\
\hline $\mathbf{3}$ & Tight seal around the mouthpiece \\
\hline $\mathbf{4}$ & Coordination between device activation and inhalation \\
\hline $\mathbf{5}$ & Slow, deep inhalation \\
\hline $\mathbf{6}$ & Breath-hold after inhalation \\
\hline
\end{tabular}

Figure I Checklist of critical steps in pMDI technique.

identify errors in accordance with manufacturer specifications, international guidelines and the existing literature. ${ }^{13,15,16,18,19,22-29}$ All observations were conducted by qualified clinical technologists trained in device use. Data on age, sex, diagnosis, duration of pMDI therapy, prior MDI training, and prior clinical trial participation were captured from medical records. Prior clinical trials at this facility included the evaluation of new dry powder devices such as the Ellipta ${ }^{\circledR}$ or Breezhaler $^{\circledR}$, subcutaneous biological therapies, or novel use of an existing dry powder device such as the Turbuhaler ${ }^{\mathbb{B}}$.

All data were analysed using SPSS software (SPSS 25.0, Armonk NY: IBM Corp). For all statistical comparisons, a 5\% level of significance was used; correspondingly $95 \%$ confidence intervals were used to describe effect size. All data were assessed for normality, and non-parametric tests were used where necessary. An inadequate inhaler technique was defined as the presence of one or more critical errors. A multivariate binomial logistic regression model was used to determine the odds of an inadequate inhaler technique and included the following covariates: age, sex, diagnosis, prior clinical trial participation, duration of prior inhaler use, and prior pMDI training.

The study was approved and conducted under the oversight of the University of Cape Town Faculty of Health Sciences Human Ethics Research Committee (HREC 430/ 2017), and in accordance with the Declaration of Helsinki. All patients provided written informed consent.

\section{Results}

During the study period, 357 consecutive asthma or COPD patients using a pressurized metered-dose inhaler were enrolled over a 14-month period. The baseline characteristics of the study participants are presented in Table 1. The mean age of participants was 52.5 years
Table I Baseline Characteristics of Study Participants Stratified by Diagnosis

\begin{tabular}{|c|c|c|c|c|}
\hline Characteristics & $\begin{array}{l}\text { Asthma } \\
(\mathrm{N}=\mathbf{2 0 5})\end{array}$ & $\begin{array}{l}\text { COPD } \\
(N=152)\end{array}$ & $\begin{array}{l}\text { Total } \\
(\mathrm{N}=357)\end{array}$ & $p$-value \\
\hline Age, mean(SD) & $45.2(15.8)$ & $62.4(8.0)$ & $52.5(15.6)$ & $<0.001 *$ \\
\hline \multicolumn{5}{|l|}{ Sex } \\
\hline Male, $n(\%)$ & $58(28.3)$ & $96(63.2)$ & 154(43.1) & $<0.001^{€}$ \\
\hline $\begin{array}{l}\text { Prior PMDI } \\
\text { experience (years), } \\
\text { median (IQR) }\end{array}$ & $15(6-26)$ & $6(3-11)$ & $10(5-20)$ & $<0.001^{*}$ \\
\hline \multicolumn{5}{|l|}{ Prior pMDI training } \\
\hline None, n(\%) & $13(6.3)$ & $19(12.5)$ & $32(9.0)$ & \\
\hline Doctor, n(\%) & $165(80.5)$ & $\begin{array}{l}118 \\
(77.6)\end{array}$ & $283(79.2)$ & $0.20^{€}$ \\
\hline Nurse, $n(\%)$ & $21(10.2)$ & II (7.2) & $32(9.0)$ & \\
\hline Pharmacist, n(\%) & $6(2.9)$ & $4(2.6)$ & $10(2.8)$ & \\
\hline \multicolumn{5}{|l|}{$\begin{array}{l}\text { Prior clinical trial } \\
\text { participation }\end{array}$} \\
\hline None, n(\%) & $150(73.2)$ & $\begin{array}{l}126 \\
(82.9)\end{array}$ & $276(77.3)$ & $0.09^{€}$ \\
\hline$<3$ trials, $\mathrm{n}(\%)$ & $34(16.6)$ & $17(11.2)$ & $51(14.3)$ & \\
\hline$\geq 3$ trials, $n(\%)$ & $21(10.2)$ & $9(5.9)$ & $30(8.4)$ & \\
\hline
\end{tabular}

Notes: *Independent samples $t$-test, ${ }^{\epsilon}$ Pearson chi-square, ${ }^{\sharp}$ Mann-Whitney U-test. Abbreviations: SD, standard deviation; IQR, interquartile range; PMDI, pressurised metered-dose inhaler.

(SD 15.6 years), and $56.7 \%$ were female. A diagnosis of asthma was present is $57.4 \%$ of participants and of COPD in $42.6 \%$. Participants had a median of 10 years (IQR 5-20) prior experience using a pMDI. The majority (79.2\%) reported receiving prior training on pMDI inhaler technique by their physician, $9 \%$ by a nurse, and $2.8 \%$ by a pharmacist. While the majority $(77.3 \%)$ of participants had never participated in a clinical trial, $14.3 \%$ had participated in fewer than 3 trials and $8.4 \%$ had participated in three or more trials. Participants with asthma were younger, more likely to be female, and had longer prior experience on a pMDI than patients with COPD (Table 1). There was no significant difference in prior pMDI training exposure and previous clinical trial participation between participants with asthma and COPD.

At least one critical error was executed by $66.7 \%$ of participants, and $24.9 \%$ made four or more critical errors (Table 2). The most common errors were: failure to exhale completely prior to pMDI activation and inhalation (49.6\%), failure to perform a slow, deep inhalation following device activation (48.7\%), and failure to perform a breath-hold at the end of inspiration (47.3\%). 
Table 2 Frequency of Critical Errors in All Participants

\begin{tabular}{|l|l|}
\hline Step & $\begin{array}{l}\text { Error Frequency } \\
(\mathbf{N}=357)\end{array}$ \\
\hline Shake the inhaler & $15.1 \%$ \\
Complete exhalation & $49.6 \%$ \\
Tight seal around the mouthpiece & $12 \%$ \\
Coordination between device activation & $25.2 \%$ \\
and inhalation & \\
Slow, deep inhalation & $48.7 \%$ \\
Breath-hold after inhalation & $47.3 \%$ \\
\hline Cumulative errors & \\
One or more error(s) & $66.7 \%$ \\
Four or more errors & $24.9 \%$ \\
\hline
\end{tabular}

Table 3 Multivariate Binomial Logistic Regression Analysis to Evaluate the Determinants of Inadequate Inhaler Technique

\begin{tabular}{|l|l|l|l|}
\hline Characteristics & Adjusted OR & $\mathbf{9 5 \%} \mathbf{C l}$ & p-value \\
\hline Age & 1.0 & $0.98-1.01$ & 0.61 \\
\hline $\begin{array}{l}\text { Sex } \\
\text { Female }\end{array}$ & Reference & & \\
Male & 0.72 & $0.42-1.2$ & 0.21 \\
\hline Diagnosis & & & \\
Asthma & Reference & & \\
COPD & 2.25 & $1.13-4.47$ & 0.02 \\
\hline Prior pMDI experience & 1.01 & $0.98-1.03$ & 0.66 \\
\hline Prior pMDI training & & & \\
None & Reference & & \\
Nurse & 0.26 & $0.03-2.55$ & 0.25 \\
Doctor & 0.08 & $0.01-0.57$ & 0.01 \\
Pharmacist & 0.02 & $0.01-0.26$ & 0.002 \\
\hline Prior clinical trial participation & & & \\
None & Reference & & \\
$<3$ trials & 0.35 & $0.19-0.66$ & 0.001 \\
$\geq 3$ trials & 0.17 & $0.07-0.42$ & $<0.001$ \\
\hline
\end{tabular}

Abbreviations: $\mathrm{OR}$, odds ratio; $\mathrm{Cl}$, confidence interval; $\mathrm{pMDI}$, pressurised metered-dose inhaler.

The multivariate logistic regression model (Table 3) revealed that the risk of a critical error was significantly increased in participants with COPD (aOR 2.25, 95\% CI 1.13-4.47), and significantly decreased in participants who were previously trained by a doctor (aOR $0.08,95 \% \mathrm{CI}$ $0.1-0.57$ ) or a pharmacist (aOR $0.02,95 \%$ CI $0.01-0.26$ ) compared to no previous training, and in participants with prior clinical trial exposure $[<3$ trials $(\mathrm{aOR} 0.35,95 \% \mathrm{CI}$ $0.19-0.66$ ) and $\geq 3$ trials (aOR $0.17,95 \%$ CI $0.07-0.42$ ). The rate of critical errors was not significantly associated with age, sex, or prior pMDI experience.
Table 4 Frequency of Critical Errors Stratified by Prior Clinical Trial Participation

\begin{tabular}{|l|l|l|l|l|l|}
\hline Step & None & $\begin{array}{l}<3 \\
\text { Trials }\end{array}$ & $\begin{array}{l}\geq 3 \\
\text { Trials }\end{array}$ & $\begin{array}{l}\text { Total } \\
(\mathbf{N}=357)\end{array}$ & $\mathbf{p}$-value \\
\hline $\begin{array}{l}\text { Shake the inhaler } \\
\text { Complete exhalation }\end{array}$ & $17 \%$ & $11.8 \%$ & $3.3 \%$ & $15.1 \%$ & $0.10 \%$ \\
$\begin{array}{l}\text { Tight seal around } \\
\text { mouthpiece }\end{array}$ & $15.2 \%$ & $37.3 \%$ & $26.7 \%$ & $49.6 \%$ & 0.003 \\
$\begin{array}{l}\text { Coordination between } \\
\text { device activation and } \\
\text { inhalation }\end{array}$ & $28.6 \%$ & $19.6 \%$ & $3.3 \%$ & $25.2 \%$ & 0.006 \\
$\begin{array}{l}\text { Slow, deep inhalation } \\
\text { Breath-hold after } \\
\text { inhalation }\end{array}$ & $57.2 \%$ & $27.5 \%$ & $6.7 \%$ & $48.7 \%$ & $<0.001$ \\
\hline $\begin{array}{l}\text { Cumulative errors } \\
\text { One or more error(s) } \\
\text { Four or more errors }\end{array}$ & $74.6 \%$ & $47.4 \%$ & $10 \%$ & $47.3 \%$ & $<0.001$ \\
\hline
\end{tabular}

Notes: *Fisher's exact test. Pearson chi-square for all other comparisons.

The rate of critical errors showed a graded reduction with increased prior clinical trial participation for all critical errors (Table 4). Overall, $74 \%$ of participants with 3 or more clinical trials experience had a perfect inhaler technique compared to $52.9 \%$ of those with less than 3 trials experience and only $24.4 \%$ of those who had never participated in a clinical trial. Only $3.3 \%$ of the most trialexperienced participants had a grossly inadequate technique (4 or more errors) compared to $29 \%$ of trial-naïve participants. The magnitude of reduction in the error rate of each step, in participants with no clinical trial experience versus those with participation in three or more clinical trials, ranged from $50.8 \%$ to $88.5 \%$, with a statistically significant reduction in five out of six critical error steps (Table 4).

\section{Discussion}

Incorrect inhaler use is associated with poorer health outcomes, reduced quality of life, and higher healthcare utilisation in patients with asthma and COPD. ${ }^{4,7,13,15}$ Identifying and characterizing incorrect inhaler use is a crucial first step toward designing context-specific interventions for improving inhaler technique. This study of inhaler technique in a mixed population of asthma and COPD patients at a specialist respiratory service in subSaharan Africa found, not unexpectedly, a high rate of critical errors in pMDI use, with over two-thirds (66.7\%) of participants making at least one critical error. Similarly, a quarter of participants made errors in more than half $(\geq 4$ / 
6) of the critical steps. A novel finding in this study is that previous participation in a clinical trial was associated with a $65 \%(\mathrm{aOR} 0.35,95 \%$ CI $0.19-0.66)$ reduction in the risk of making an error in one or more of the six steps. Participation in three or more previous clinical trials reduced the risk of errors by $83 \%$ (aOR $0.17,95 \% \mathrm{CI}$ 0.07-0.42).

These findings are alarming for a country with one of the highest asthma mortality rates and the highest incidence of COPD in the world. ${ }^{1,30,31}$ Identifying inhaler misuse and improving inhaler technique is a low-cost scalable intervention to improve asthma and COPD care in this resourcelimited setting. The failure of a longer duration of pMDI use to translate into improved inhaler technique may reflect the fact that most errors are repetitive and persist over time, and that patients may be susceptible to overconfidence in device use which may further perpetuate inhaler misuse. ${ }^{23,32}$ Moreover, the gains in experience in inhaler practice over time may be offset by advancing age, the onset of comorbidities, and disease progression which may all negatively affect inhaler technique. $^{17,33,34}$

Similar to studies in other settings, the most commonly performed errors were failure of complete exhalation prior to inhaler use, failure to perform a slow deep inhalation following device activation, and failure to maintain a breath-hold after complete inspiration. ${ }^{17,22,32,35,36}$ Errors in exhalation and in breath-holding have been shown to significantly reduce drug deposition and may be linked to uncontrolled asthma. ${ }^{22,37}$ Although not as frequent, errors in coordinating device activation with breathing were made in over a quarter of the participants $(25.2 \%)$, and confirms this widely-held disadvantage of pMDIs which has negative consequences for treatment outcomes. ${ }^{22}$ These breathing errors were more common than device handling errors which are more commonly seen with DPIs. ${ }^{22}$ The use of a spacer device may simplify inhaler use by obviating the need for coordinating device activation and the correct rate and depth of inhalation. ${ }^{38}$ Moreover, spacer devices may enhance drug deposition in the lung by reducing drug particle velocity due to air resistance and reducing delivered particle size by evaporation. ${ }^{38}$ However, spacer devices are relatively large, cumbersome, and infrequently carried with patients, which may limit their use in practice. ${ }^{29}$ Concerningly, spacer device use has recently been associated with poorer inhaler technique and lower effective dosing owing to increased task complexity. $^{29,33}$

The risk of making one or more critical errors was increased in COPD (aOR 2.25, 95\% CI 1.13-4.47) compared with asthma and persisted in the model when adjusted for age, prior inhaler experience, and previous inhaler training. This finding has been variably reported in studies comparing inhaler technique in patients with asthma and COPD. ${ }^{14,17}$ While a study by Melanie et al found a higher risk of inhaler technique errors in patients with COPD, the association diminished after adjusting for age and prior inhaler training. ${ }^{14}$ Similarly, no significant difference in the rate of errors was reported by other studies comparing inhaler technique in patients with asthma or COPD. ${ }^{14,17,23,29,32,34,39}$

In our comparison of errors made in individual steps, participants with COPD made significantly more breathing errors (failure of complete exhalation, and failure to take a slow, deep inhalation). It is plausible that these limitations are related to the physiological and mechanical features of COPD, including more severe limitations to airflow, and a higher functional residual capacity. Furthermore, it has been shown that inhaler errors are associated with peak flow rate, and patients with COPD have been shown to have significantly lower peak inspiratory and expiratory flow rates than patients with asthma. ${ }^{39}$ In addition, patients with COPD are more likely to have co-morbidities such as heart failure, cognitive impairment, and weak grip strength, which have been associated with poorer inhaler technique. ${ }^{5,33,34,40}$ Age, sex and duration of prior pMDI experience did not significantly predict the risk of inhaler technique error and is consistent with published studies and systematic reviews. ${ }^{15,17,34}$

Prior inhaler technique trainer was associated with a variable reduction in risk of errors dependent on the profession of the trainer, the best appearing to be a pharmacist (aOR 0.02 , 95\% CI 0.01-0.26) followed by a doctor (aOR 0.08, 95\% CI 0.01-0.57). This is consistent with previous studies demonstrating the effectiveness of training interventions for sustained improvement in inhaler use. ${ }^{21,41}$ Inhaler training conducted by doctors was associated with a reduced risk of inhaler errors and has been demonstrated to be a significant predictor of flawless inhaler technique. ${ }^{23,29}$ Sadly, the majority of doctors do not check inhaler technique when inhaler therapy is prescribed, believing instead that this important intervention will be performed elsewhere within the healthcare system. $^{42,43}$ In this study, training by a pharmacist was associated with the greatest reduction in the risk for inhaler errors and is consistent with studies demonstrating high levels of effectiveness in pharmacist-driven inhaler training interventions. ${ }^{44-46}$ The most appropriate and effective person to provide inhaler technique training is challenging to 
designate in low-resource settings where the ratio of patients to doctors or pharmacists are very high. Worryingly, prior inhaler training by a nurse did not reduce the risk of inhaler errors in this study (aOR 0.26, 95\% CI 0.03-2.55). This has major implications for nurse-driven primary healthcare services, such as in low and middle-income countries, where the majority of patients access care from a nurse practitioner and require referral onward to a doctor only in highly selected cases. This finding likely reflects a lack of training and opportunity for nurses to learn about inhaler technique, as the success of the nurse-driven antiretroviral therapy programme in South Africa, the largest in the world, is a reassuring example that task-shifting and upskilling of primary care nurses is possible. ${ }^{47}$ Significant training of the nursing fraternity will be required for a widespread inhaler technique intervention in a nurse-driven primary care setting.

The major novel finding of this study was that prior participation in clinical trials significantly reduced the risk of inhaler errors. Increasing clinical trial participation incrementally reduced the risk of errors. A perfect inhaler technique was observed in $25.4 \%$ of participants with no clinical trial experience and in $73.3 \%$ of participants enrolled previously in more than three clinical trials. It is explicable that participants who have previously participated in clinical trials have better inhaler technique, as clinical trials often include frequent standardised highquality device education and training. While it is possible that the lower rate and risk of inhaler errors in participants with clinical trial experience reflects the selection bias of clinical trials, the clear graded response of the risk reduction in error rate with increasing clinical trial participation $(0, \leq 3,>3)$ is highly suggestive of a true intervention-like effect. It has also, to the best of our knowledge, never been shown that inhaler technique adequacy during clinical trial participation persists beyond the actual clinical trial period. This finding highlights a potentially unintended but advantageous result of asthma and COPD clinical trial participation. Encouraging patients to participate in clinical trials should always be considered in the interest of promoting science and access to new interventions, provided the patient is willing, but this study suggests that clinical trials may have unintended but beneficial longterm post-trial consequences. The graded association also suggests that directed interventions for inhaler technique training will likely have to be repetitive, intensive, and prolonged over the course of the patient's inhaler use, and that many of the failed inhaler intervention studies may have just been too short and not intensive enough. ${ }^{48-52}$
This study is one of only a few observational studies of inhaler technique in Africa ${ }^{20,53}$ but has some limitations. Although moderately sized, and conducted in a prospective observational manner, evaluation of inhaler technique is subject to inter- and intra-rater variability. This was minimised by using a few select and highly trained lung function technologists. The association between previous clinical trial experience and inhaler adequacy may be confounded by the differential inclusion of participants with adequate technique into clinical trials. However, the majority of the trials conducted at this site did not require perfect pMDI technique as a study entry requirement as they were evaluating new dry powder devices such as the Ellipta ${ }^{\circledR}$ or Breezhaler ${ }^{\circledR}$, subcutaneous biological therapies, or novel use of an existing dry powder device such as the Turbuhaler ${ }^{\circledR}$. The association may, therefore, be better explained by pMDI inhaler technique being evaluated and reinforced routinely during the trial. The limited access to clinical trial participation in rural areas may limit the generalisability of our findings with regards to trial participation as a potential intervention, but the implication remains that long-term intensive patient training is required to impact on inhaler technique. A major limitation of inhaler technique studies is the lack of consensus on a definition of inadequate inhaler technique, and socalled critical and non-critical errors. We used a common sixpoint checklist including known critical errors demonstrated to reduce the effective dosing and impact on treatment outcome. Nonetheless, there remains a desperate need for further validation of a standardised tool to advance this field of study.

Poor inhaler technique is common and is relatively resistant to improvement as demonstrated by many failed short-term interventions to improve technique. This study found a high rate of critical inhaler technique errors in a mixed population of asthma and COPD patients; however, previous clinical trial participation significantly reduced the risk of errors. The graded reduction in the likelihood of errors, as well as error rate, with increasing trial participation, suggests that long-term intensive inhaler training and review may be required to impact on inhaler error rates. Who is best suited to deliver this training, how often, and for how long, remain unanswered questions in this field.

\section{Acknowledgments}

We thank the staff of the Lung Institute for their contribution to this study and for performing the inhaler technique assessments. 


\section{Disclosure}

RVZS has received honoraria for advisory board participation and academic presentations from Astra-Zeneca, GSK, ASPEN, Novartis, Roche, MSD, Pfizer, Adcock-Ingram all outside of the scope of this manuscript. The authors report no other conflicts of interest in this work.

\section{References}

1. Soriano JB, Abajobir AA, Abate KH, Collaborators GBDCRD. Global, regional, and national deaths, prevalence, disability-adjusted life years, and years lived with disability for chronic obstructive pulmonary disease and asthma, 1990-2015: a systematic analysis for the global burden of disease study 2015. Lancet Respir Med. 2017;5(9):691-706. doi:10.1016/S2213-2600(17)30293-X

2. Global Initiative for Asthma. Global Strategy for Asthma Management and Prevention. 2019.

3. Global Initiative for Chronic Obstructive Lung Disease. Global Strategy for the Diagnosis, Management, and Prevention of Chronic Obstructive Pulmonary Disease (2019 Report). 2019.

4. Fink JB. Inhalers in asthma management: is demonstration the key to compliance? Respir Care. 2005;50(5):598-600.

5. Dudvarski Ilic A, Zugic V, Zvezdin B, et al. Influence of inhaler technique on asthma and COPD control: a multicenter experience. Int J Chron Obstruct Pulmon Dis. 2016;11:2509-2517. doi:10.2147/ COPD.S114576

6. Braido F, Chrystyn H, Baiardini I, et al. trying, but failing - the role of inhaler technique and mode of delivery in respiratory medication adherence. J Allergy Clin Immunol Pract. 2016;4(5):823-832. doi:10.1016/j.jaip.2016.03.002

7. Kocks JWH, Chrystyn H, van der Palen J, et al. Systematic review of association between critical errors in inhalation and health outcomes in asthma and COPD. NPJ Prim Care Respir Med. 2018;28(1):43. doi:10.1038/s41533-018-0110-x

8. Pike KC, Levy ML, Moreiras J, Fleming L. Managing problematic severe asthma: beyond the guidelines. Arch Dis Child. 2018;103 (4):392-397. doi:10.1136/archdischild-2016-311368

9. McGrady ME, Hommel KA. Medication adherence and health care utilization in pediatric chronic illness: a systematic review. Pediatrics. 2013;132(4):730-740. doi:10.1542/peds.2013-1451

10. Pavord ID, Beasley R, Agusti A, et al. After asthma: redefining airways diseases. Lancet. 2018;391(10118):350-400. doi:10.1016/ S0140-6736(17)30879-6

11. Clark VL, Gibson PG, Genn G, Hiles SA, Pavord ID, McDonald VM. Multidimensional assessment of severe asthma: a systematic review and meta-analysis. Respirology. 2017;22 (7):1262-1275. doi:10.1111/resp. 13134

12. Giraud V, Roche N. Misuse of corticosteroid metered-dose inhaler is associated with decreased asthma stability. Eur Respir J. 2002;19 (2):246-251. doi:10.1183/09031936.02.00218402

13. Lindgren S, Bake B, Larsson S. Clinical consequences of inadequate inhalation technique in asthma therapy. Eur J Respir Dis. 1987;70 (2):93-98.

14. Melani AS, Bonavia M, Cilenti V, et al. Inhaler mishandling remains common in real life and is associated with reduced disease control. Respir Med. 2011;105(6):930-938. doi:10.1016/j.rmed.2011.01.005

15. Usmani OS, Lavorini F, Marshall J, et al. Critical inhaler errors in asthma and COPD: a systematic review of impact on health outcomes. Respir Res. 2018;19(1):10. doi:10.1186/s12931-017-0710-y

16. Al-Jahdali H, Ahmed A, Al-Harbi A, et al. Improper inhaler technique is associated with poor asthma control and frequent emergency department visits. Allergy Asthma Clin Immunol. 2013;9(1):8. doi:10.1186/1710-1492-9-8
17. Ocakli B, Ozmen I, Tuncay EA, et al. A comparative analysis of errors in inhaler technique among COPD versus asthma patients. Int J Chron Obstruct Pulmon Dis. 2018;13:2941-2947. doi:10.2147/COPD.S178951

18. Chrystyn H, van der Palen J, Sharma R, et al. Device errors in asthma and COPD: systematic literature review and meta-analysis. NPJ Prim Care Respir Med. 2017;27(1):22. doi:10.1038/s41533-017-0016-z

19. Sanchis J, Gich I, Pedersen S. aerosol drug management improvement T. Systematic review of errors in inhaler use: has patient technique improved over time? Chest. 2016;150(2):394-406. doi:10.1016/j.chest.2016.03.041

20. Onyedum C, Desalu O, Nwosu N, Chukwuka C, Ukwaja K, Ezeudo C. Evaluation of inhaler techniques among asthma patients seen in Nigeria: an observational cross sectional study. Ann Med Health Sci Res. 2014;4(1):67-73. doi:10.4103/2141-9248.126617

21. Klijn SL, Hiligsmann M, Evers S, Roman-Rodriguez M, van der Molen T, van Boven JFM. Effectiveness and success factors of educational inhaler technique interventions in asthma \& COPD patients: a systematic review. NPJ Prim Care Respir Med. 2017;27 (1):24. doi:10.1038/s41533-017-0022-1

22. Price DB, Roman-Rodriguez M, McQueen RB, et al. Inhaler errors in the CRITIKAL study: type, frequency, and association with asthma outcomes. J Allergy Clin Immunol Pract. 2017;5(4):1071-1081 e1079. doi:10.1016/j.jaip.2017.01.004

23. Arora P, Kumar L, Vohra V, et al. Evaluating the technique of using inhalation device in COPD and bronchial asthma patients. Respir Med. 2014;108(7):992-998. doi:10.1016/j.rmed.2014.04.021

24. Boise E, Rotella M. ABCs of asthma inhaler and device training. Int Forum Allergy Rhinol. 2015;5(Suppl 1):S71-75. doi:10.1002/ alr.21605

25. Inhaler Error Steering C, Price D, Bosnic-Anticevich S, Briggs A, et al. Inhaler competence in asthma: common errors, barriers to use and recommended solutions. Respir Med. 2013;107(1):37-46. doi:10.1016/j.rmed.2012.09.017

26. Mahon J, Fitzgerald A, Glanville J, et al. Misuse and/or treatment delivery failure of inhalers among patients with asthma or COPD: a review and recommendations for the conduct of future research. Respir Med. 2017;129:98-116. doi:10.1016/j.rmed.2017.05.004

27. Gregoriano C, Dieterle T, Breitenstein AL, et al. Use and inhalation technique of inhaled medication in patients with asthma and COPD: data from a randomized controlled trial. Respir Res. 2018;19(1):237. doi:10.1186/s12931-018-0936-3

28. van der Palen J, Thomas M, Chrystyn H, et al. A randomised open-label cross-over study of inhaler errors, preference and time to achieve correct inhaler use in patients with COPD or asthma: comparison of ELLIPTA with other inhaler devices. NPJ Prim Care Respir Med. 2016;26(1):16079. doi:10.1038/npjpcrm.2016.79

29. Bartolo K, Balzan M, Schembri EL, et al. Predictors of correct technique in patients using pressurized metered dose inhalers. $B M C$ Pulm Med. 2017;17(1):47. doi:10.1186/s12890-017-0386-6

30. Buist AS, McBurnie MA, Vollmer WM, et al. International variation in the prevalence of COPD (the BOLD Study): a population-based prevalence study. Lancet. 2007;370(9589):741-750. doi:10.1016/ S0140-6736(07)61377-4

31. Network GA. The Global Asthma Report 2018. Auckland, New Zealand: Global Asthma Network; 2018.

32. Luczak-Wozniak K, Dabrowska M, Domagala I, et al. Mishandling of pMDI and DPI inhalers in asthma and COPD - Repetitive and non-repetitive errors. Pulm Pharmacol Ther. 2018;51:65-72. doi:10.1016/j.pupt.2018.06.002

33. Sadowski CA, Cor K, Cave A, Banh HL. Administration technique and acceptance of inhaler devices in patients with asthma or COPD. Ann Pharmacother. 2015;49(6):639-648. doi:10.1177/1060028015579097

34. Chorao P, Pereira AM, Fonseca JA. Inhaler devices in asthma and COPD-an assessment of inhaler technique and patient preferences. Respir Med. 2014;108(7):968-975. doi:10.1016/j.rmed.2014.04.019 
35. Melzer AC, Ghassemieh BJ, Gillespie SE, et al. Patient characteristics associated with poor inhaler technique among a cohort of patients with COPD. Respir Med. 2017;123:124-130. doi:10.1016/j.rmed. 2016.12.011

36. Sulaiman I, Seheult J, MacHale E, et al. Irregular and ineffective: a quantitative observational study of the time and technique of inhaler use. J Allergy Clin Immunol Pract. 2016;4(5):900-909e902. doi:10. 1016/j.jaip.2016.07.009

37. Hindle M, Newton D, Chrystyn H. Investigations of an optimal inhaler technique with the use of urinary salbutamol excretion as a measure of relative bioavailability to the lung. Thorax. 1993;48 (6):607-610. doi:10.1136/thx.48.6.607

38. Capstick TG, Clifton IJ. Inhaler technique and training in people with chronic obstructive pulmonary disease and asthma. Expert Rev Respir Med. 2012;6(1):91-101. (). doi:10.1586/ers.11.89

39. Takaku Y, Kurashima K, Ohta C, et al. How many instructions are required to correct inhalation errors in patients with asthma and chronic obstructive pulmonary disease? Respir Med. 2017;123:110-115. doi:10.1016/j.rmed.2016.12.012

40. Dalcin PDTR, Grutcki DM, Laporte PP, Lima P, Menegotto S, Pereira R. Factors related to the incorrect use of inhalers by asthma patients. J Bras Pneumol. 2014;40(1):13-20. doi:10.1590/S1806-371 32014000100003

41. Pothirat C, Chaiwong W, Phetsuk N, Pisalthanapuna S, Chetsadaphan N, Choomuang W. Evaluating inhaler use technique in COPD patients. Int $J$ Chron Obstruct Pulmon Dis. 2015;10:1291-1298. doi:10.2147/COPD.S85681

42. Plaza V, Sanchis J, Roura P, et al. Physicians' knowledge of inhaler devices and inhalation techniques remains poor in Spain. J Aerosol Med Pulm Drug Deliv. 2012;25(1):16-22. doi:10.1089/jamp. 2011.0895

43. Steurer-Stey C, Fletcher M, Vetter W, Steurer J. Patient education in asthma: a survey of physicians' knowledge of the principles and implementation of self management in practice. Swiss Med Wkly. 2006;136(35-36):561-565.

44. Axtell S, Haines S, Fairclough J. Effectiveness of various methods of teaching proper inhaler technique. J Pharm Pract. 2017;30(2):195-201. doi:10.1177/0897190016628961
45. Bouwmeester C, Kraft J, Bungay KM. Optimizing inhaler use by pharmacist-provided education to community-dwelling elderly. Respir Med. 2015;109(10):1363-1368. doi:10.1016/j.rmed.2015.07. 013

46. Garcia-Cardenas V, Sabater-Hernandez D, Kenny P, MartinezMartinez F, Faus MJ, Benrimoj SI. Effect of a pharmacist intervention on asthma control. A cluster randomised trial. Respir Med. 2013;107(9):1346-1355. doi:10.1016/j.rmed.2013.05.014

47. Jones M, Cameron D. Evaluating 5 years' NIMART mentoring in South Africa's HIV treatment programme: successes, challenges and future needs. S Afr Med J. 2017;107(10):839-842. doi:10.7196/ SAMJ.2017.v107i10.12392

48. Basheti IA, Armour CL, Bosnic-Anticevich SZ, Reddel HK. Evaluation of a novel educational strategy, including inhaler-based reminder labels, to improve asthma inhaler technique. Patient Educ Couns. 2008;72(1):26-33. doi:10.1016/j.pec.2008.01.014

49. Bosnic-Anticevich SZ, Sinha H, So S, Reddel HK. Metered-dose inhaler technique: the effect of two educational interventions delivered in community pharmacy over time. J Asthma. 2010;47 (3):251-256. doi:10.3109/02770900903580843

50. De Blaquiere P, Christensen DB, Carter WB, Martin TR. Use and misuse of metered-dose inhalers by patients with chronic lung disease. A controlled, randomized trial of two instruction methods. Am Rev Respir Dis. 1989;140(4):910-916. doi:10.1164/ajrccm/140.4.910

51. Hesselink AE, Penninx BW, van der Windt DA, et al. Effectiveness of an education programme by a general practice assistant for asthma and COPD patients: results from a randomised controlled trial. Patient Educ Couns. 2004;55(1):121-128. doi:10.1016/j.pec. 2003.08.007

52. Rootmensen GN, van Keimpema AR, Looysen EE, van der Schaaf L, de Haan RJ, Jansen HM. The effects of additional care by a pulmonary nurse for asthma and COPD patients at a respiratory outpatient clinic: results from a double blind, randomized clinical trial. Patient Educ Couns. 2008;70(2):179-186. doi:10.1016/j.pec. 2007.09.021

53. Vadnerwagen J, Smith C. Inhaler technique in patients attending an urban pulmonology practice. Afr J Thoracic Crit Care Med. 2017;23 (1):5-7.

International Journal of Chronic Obstructive Pulmonary Disease

\section{Publish your work in this journal}

The International Journal of COPD is an international, peer-reviewed journal of therapeutics and pharmacology focusing on concise rapid reporting of clinical studies and reviews in COPD. Special focus is given to the pathophysiological processes underlying the disease, intervention programs, patient focused education, and self management protocols. This journal is indexed on PubMed Central, MedLine and CAS. The manuscript management system is completely online and includes a very quick and fair peer-review system, which is all easy to use. Visit http://www.dovepress.com/testimonials.php to read real quotes from published authors. 